\title{
Diversity of Alkaliphilic Halobacteria: Proposals for Transfer of Natronobacterium vacuolatum, Natronobacterium magadii, and Natronobacterium pharaonis to Halorubrum, Natrialba, and Natronomonas gen. nov., Respectively, as Halorubrum vacuolatum comb. nov., Natrialba magadii comb. nov., and Natronomonas pharaonis comb. nov., Respectively
}

\author{
MASAHIRO KAMEKURA, ${ }^{1 *}$ MICHAEL L. DYALL-SMITH, ${ }^{2}$ VIVEK UPASANI ${ }^{3}$ ANTONIO VENTOSA, ${ }^{4}$ \\ AND MORRIS KATES ${ }^{5}$ \\ Noda Institute for Scientific Research, 399 Noda, Noda-shi, Chiba-ken 278, Japan ${ }^{1}$; Department of Microbiology, \\ University of Melbourne, Parkville 3052, Australia ${ }^{2}$; M. G. Science Institute, Navrangpura, Ahmedabad 380009 , \\ Gujarat, India ${ }^{3}$; Department of Microbiology and Parasitology, University of Sevilla, 41012 Seville, Spain ${ }^{4}$; and \\ Department of Biochemistry, University of Ottawa, Ottawa, Ontario K1N 6N5, Canada ${ }^{5}$
}

\begin{abstract}
The 16S rRNA genes of three species of the genus Natronobacterium (Natronobacterium gregoryi, Natronobacterium pharaonis, and Natronobacterium vacuolatum) were sequenced and compared to that of the previously sequenced species Natronobacterium magadii. The sequences revealed that Natronobacterium pharaonis was phylogenetically distinct from the other members of the genus and also from other recognized genera of the family Halobacteriaceae. However, Natronobacterium vacuolatum and Natronobacterium magadii were found to be most closely related to the genera Halorubrum and Natrialba, respectively. An unidentified haloalkaliphile, strain SSL1, was also closely related to Natronobacterium magadii and Natrialba asiatica. On the basis of phylogenetic tree reconstructions, signature bases specific for individual genera, and sequences of spacer regions between 16 and $23 S$ rRNA genes, we propose the following changes: Natronobacterium pharaonis to be transferred to Natronomonas gen. nov. as Natronomonas pharaonis gen. nov., comb. nov.; Natronobacterium vacuolatum to be transferred to the genus Halorubrum as Halorubrum vacuolatum comb. nov.; and Natronobacterium magadii to be transferred to the genus Natrialba as Natrialba magadii.
\end{abstract}

The extremely halophilic, aerobic Archaea are classified within the family Halobacteriaceae, which currently contains nine valid genera: Halobacterium, Halococcus, Haloarcula, Haloferax, Halorubrum, Halobaculum, Natrialba, Natronobacterium, and Natronococcus $(3,5,7,13,16,17)$.

The alkaliphilic members of the Halobacteriaceae form a distinct physiological group as they require not only high $\mathrm{NaCl}$ concentrations but also high pH (between 8.5 and 11) and low $\mathrm{Mg}^{2+}$ concentrations (less than $10 \mathrm{mM}$ ) for growth. They have been isolated from a variety of alkaline, hypersaline lakes and soils $(3,15,18,20-22)$. Microscopically, the initial isolates consisted of rods and cocci and were accordingly separated into two genera, Natronobacterium and Natronococcus, by Tindall et al. (21). Natronobacterium currently contains four recognized species, Natronobacterium gregoryi, Natronobacterium magadii, Natronobacterium pharaonis, and Natronobacterium vacuolatum, with Natronobacterium gregoryi as the type species. The present classification of these isolates is based largely on chemotaxonomic criteria, particularly phenotypic properties and lipid composition. Glycolipid analysis, which has been of great use in the taxonomy of the neutrophilic halobacteria, has had little impact in the classification of the natronobacteria, as these lack major amounts of glycolipids in their membranes (3, $15)$. The complete sequence of the $16 \mathrm{~S}$ rRNA gene of only one species, Natronobacterium magadii, has been reported, and

* Corresponding author. Mailing address: Noda Institute for Scientific Research, 399 Noda, Noda-shi, Chiba-ken 278, Japan. Phone: 81-471-23-5573. Fax: 81-471-23-5959. E-mail: mkamekur@supernig .nig.ac.jp. comparison to other halobacteria has clearly shown that it represents a distinct genus $(7,12)$. However, the sequences of the other three species of Natronobacterium (Natronobacterium gregoryi, Natronobacterium pharaonis, and Natronobacterium vacuolatum) have not been published, so phylogenetic support for their inclusion in this genus is lacking. DNA-DNA hybridization of the four species indicated that they have very little sequence homology (31 to $38 \%$ ) (15), and while this is good evidence for their classification as separate species, it does not preclude their representing different genera.

The aim of this study was to determine the phylogenetic relationships among the natronobacteria and in particular to ascertain whether the four members of the genus Natronobacterium were indeed close relatives. For this purpose, $16 \mathrm{~S}$ rRNA sequences of the three unsequenced species of Natronobacterium and of one unclassified haloalkaliphilic strain, SSL1, were determined, as well as sequences from four other strains of halobacteria. These sequences were incorporated into phylogenetic tree reconstructions of the family Halobacteriaceae.

\section{MATERIALS AND METHODS}

Bacterial strains and culture conditions. The following strains of the genus Natronobacterium were used in this study: Natronobacterium gregoryi NCIMB $2189^{\mathrm{T}}$. Natronobacterium pharaonis JCM $8858^{\mathrm{T}}$ (derived from DSM $2160^{\mathrm{T}}$ via IFO $14720^{\mathrm{T}}$ ), Natronobacterium vacuolatum JCM $9060^{\mathrm{T}}$ (deposited by W. D. Grant), and strain SSL1 (microscopically long rods, originally isolated from an alkaline saline brine from Sambhar Salt Lake, India, and deposited with the American Type Culture Collection as Natronobacterium sp. strain ATCC 43988) $(22,23)$. These strains were grown at $37^{\circ} \mathrm{C}$ in haloalkaliphile medium as previously described $(20,23)$.

Halobacterium trapanicum NCIMB 767 was obtained from the National Collection of Industrial and Marine Bacteria in 1994 and deposited as JCM 8979. Three species of the genus Halococcus (Halococcus saccharolyticus ATCC 49257, 
Halococcus salifodinae DSM 8989, and Halococcus turkmenicus VKM B-1734) were also obtained from culture collections and cultivated as described previously (7).

Sequencing of 16S rRNA genes and thin-layer chromatographic analysis of polar lipids. Genomic DNAs from the four species of Natronobacterium were extracted as described before (7). Halobacterium trapanicum JCM 8979 and species of Halococcus which do not lyse with $N$-lauroylsarcosine were ground with quartz sand, and DNA was recovered by ethanol precipitation. 16S rRNAencoding genes were amplified by PCR, cloned into plasmid pUC119, and sequenced $(7,8)$. Final sequences of these genes were unambiguous, as regions which were difficult to read on one strand were easily read by sequencing the complementary strand. Phylogenetic tree reconstructions based on the $16 \mathrm{~S}$ rRNA sequences were performed as described previously (7).

Membrane lipids were extracted, and thin-layer chromatography was performed as described before (7).

Sequencing of spacer regions. Genomic DNAs from five species of the genus Halonibrum (Halorubrum saccharovorum, Halorubrum sodomense, Halorubrum lacusprofundi, Halorubrum coriense, and Halorubrum distributum) were extracted (7) and kept at $-30^{\circ} \mathrm{C}$. Spacer regions between the $16 \mathrm{~S}$ rRNA and $23 \mathrm{~S}$ rRNA genes from the three species of the genus Natronobacterium and the five species of the genus Halorubrum were amplified by PCR with a set of specific oligonucleotide primers. The sense primer, 5'-TTAAGTCGTAACAAGGTAGCCGT $\mathrm{AG}$, was based on the sequence from nucleotides 2332 to 2356 of the Halobacterium halobium rRNA operon (accession no. X03407), and the antisense primer, 3 '-CCTGCACGGTTCGACGCTATTCG, was designed based from nucleotides 2959 to 2981 of the same sequence. Both primers are situated in highly conserved regions. PCR products, which were expected to overlap by 51 bp with the $3^{\prime}$ termini of the $16 \mathrm{~S}$ rRNA genes and by 71 bp with the $5^{\prime}$ termini of the $23 \mathrm{~S}$ rRNA genes, were cloned and sequenced as described above. Sequences of spacer regions from the following halobacteria were taken or extracted from operon sequences deposited with databases: Halobacterium cutirubrum K02971, Halobacterium halobium X03407, Halococcus morrhuae X72588, Haloferax volcanii M19341, and Natronobacterium magadii X72495.

Nucleotide sequence accession numbers. The 16S rRNA gene sequences for Natronobacterium gregoryi, Natronobacterium pharaonis, Natronobacterium vacuolatum, Natronobacterium sp. strain SSL1, and Halobacterium trapanicum JCM 8979 were deposited in the DDBJ under accession numbers D87970, D87971, D87972, D88256, and D63786, respectively.

The sequences of the spacer regions for Halorubrum sodomense, Halorubrum saccharovorum, Halorubrum lacusprofundi, Halorubrum distributum, Halorubrum coriense, Natronobacterium pharaonis, Natronobacterium gregoryi, and $\mathrm{Na}$ tronobacterium vacuolatum were deposited in the DDBJ under accession numbers AB003404, AB003405, AB003406, AB003407, AB003408, AB003409, $\mathrm{AB} 003410$, and $\mathrm{AB} 003411$, respectively.

\section{RESULTS}

Nucleotide sequences of $16 \mathrm{~S}$ rRNA-encoding genes. The $16 \mathrm{~S}$ rRNA genes from four alkaliphilic halobacteria (Natronobacterium gregoryi, Natronobacterium pharaonis, Natronobacterium vacuolatum, and strain SSL1) were sequenced and compared to the previously determined sequences of Natronobacterium magadii, two species of the genus Natronococcus, and other closely related species. The lengths of the genes from the five Natronobacterium strains were 1,465 to $1,468 \mathrm{bp}$. The longest 16S rRNA gene from the Halobacteriaceae reported so far is that of Halococcus morrhuae (1,475 bp), and the shortest one is that of Natronobacterium pharaonis $(1,465 \mathrm{bp})$.

Devereux et al. (1) and Fry et al. (2) proposed that a $16 \mathrm{~S}$ rRNA similarity value less than 93 to $95 \%$ indicated that two organisms belonged to different genera. Surprisingly, when the similarity values of the four recognized members of the genus Natronobacterium were examined, all were below $92 \%$ (the highest similarity, $91.9 \%$, was observed between Natronobacterium gregoryi and Natronobacterium magadii), indicating that the four species may be sufficiently different to warrant classification in different genera. Natronobacterium pharaonis and Natronobacterium vacuolatum showed particularly weak similarities to each other ( $88.3 \%$ ), to Natronobacterium gregoryi ( 88.5 and $88.1 \%$, respectively), and to Natronobacterium magadii (88.8 and $87.1 \%$, respectively). Natronobacterium magadii was most similar to the strain SSL1 $(95.9 \%)$, and similarity to Natrialba asiatica $172 \mathrm{P} 1$ was $93.3 \%$. The similarity of strain SSL1 to Natrialba asiatica was even greater $(96.6 \%)$.

The 16S rRNA gene from Halobacterium trapanicum JCM
8979 (a culture obtained from the National Collection of Industrial and Marine Bacteria in 1994; see Materials and Methods) was also sequenced and found to be almost indistinguishable from those of two Halococcus morrhuae strains (98.6 to 98.9\% sequence similarity).

Phylogenetic tree reconstruction. The sequences of almost all of the $16 \mathrm{~S}$ rRNA genes determined so far by us ( 25 of 37 sequences, including those determined in this work) are unambiguous. Although the 5'- and 3 '-terminal sequences of the genes are those of the PCR primers, $20 \mathrm{bp}$ each, these regions are highly conserved as revealed by several sequences determined from genes obtained by the conventional cloning methods. Replacement of $\mathrm{C}$ by $\mathrm{T}$ in one position in the $3^{\prime}$-terminal antisense primer region has been reported only for the two $16 \mathrm{~S}$ rRNA genes (i.e., A and B) of Haloarcula marismortui. Several strains also show replacement of the $3^{\prime}$-terminal $\mathrm{T}$ by $\mathrm{A}$. The sequences determined in the present study were aligned with those previously reported (by us and by other groups), and used to reconstruct phylogenetic trees. Positions with any deletions or uncertain alignment were removed, and the remaining 1,371 positions were used to construct the trees. A variety of algorithms were utilized (maximum likelihood, maximum parsimony, and distance matrix [7]), which gave very similar topologies. A representative example is shown in Fig. 1. As anticipated from the similarity values, the four recognized $\mathrm{Na}$ tronobacterium species and strain SSL1 did not form a monophyletic group but were distributed throughout the tree. $\mathrm{Na}$ tronobacterium gregoryi, the type species, branched just before the natronococci, whereas Natronobacterium magadii and strain SSL1 branched before Natrialba. The exact branching order of Natronobacterium magadii and SSL1 was not clear in parsimony or distance matrix trees, but the bootstrap values indicate a clear separation of Natronobacterium magadii and Natronobacterium gregoryi. Natronobacterium vacuolatum was most closely related to the genus Halorubrum.

Natronobacterium pharaonis turned out to be only distantly related to the other genera. Even the sequence most similar to that of Natronobacterium pharaonis, i.e., Haloarcula marismortui A, showed a low similarity value of $89.9 \%$. The lack of bootstrap values at the branch point indicates that parsimony and distance methods could not confidently identify the deepest branching order in the tree (bootstrap values, 54 to $55 \%$ ) However, the maximum likelihood method (the tree shown) gave strongly supported branch lengths in this region. The evidence from sequence similarity and tree reconstructions appears to present a clear case for this isolate representing a new genus.

Signature bases of $16 \mathrm{~S}$ rRNA genes. By using the aligned sequences, a number of signature sequences (24) which were specific for each genus were revealed. These are as follows: Halobacterium (Halobacterium cutirubrum, Halobacterium halobium, and strain Y12), 77C, 106G, 128T, 213C, 222T, 407A, and 1383T; Haloarcula (Haloarcula marismortui, Haloarcula sinaïensis, Haloarcula vallismortis, and Haloarcula aidinensis), 235T, 255A, 665A, 670G, 675C, 883C, 937T, 968C, $972 \mathrm{~T}, 1173 \mathrm{~A}, 1200 \mathrm{~T}, 1202 \mathrm{~T}, 1243-$ (- means a gap), 1250A, and 1458A; Haloferax (the four recognized species), 1109A, 1218T, $1220 \mathrm{~T}$, and 1227A; Halococcus (two strains of Halococcus morrhuae, Halococcus saccharolyticus, Halococcus salifodinae, and Halobacterium trapanicum JCM 8979, but not Halococcus turkmenicus), 25T, 46C, 90C, 200C, 211C, 215A, 495A, 499A $1246 \mathrm{C}, 1271 \mathrm{~T}$, and 1280A; Natrialba (Natrialba asiatica), 385G, 502G, and 1108A; Halobaculum (Halobaculum gomorrense), 106T, 213A, 246T, 521T, 603A, 690T, 702C, 706A, 777C, and 943T; Natronobacterium gregoryi and two Natronococcus spp. (Natronococcus occultus and Natronococcus amylolyticus), 


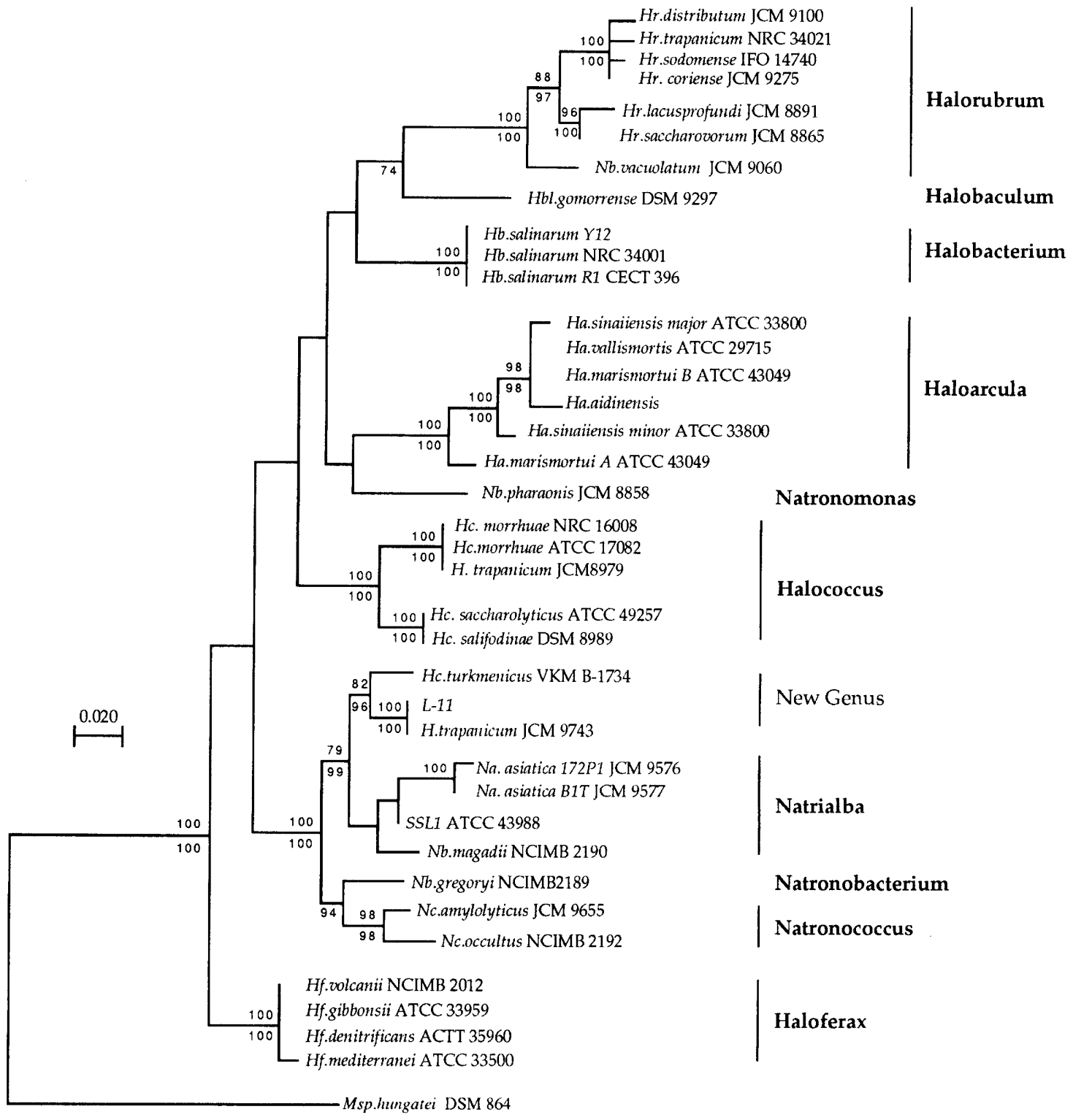

FIG. 1. Phylogenetic tree reconstruction of the Halobacteriaceae with complete 16S rRNA sequences. The representative tree shown here was derived by using maximum likelihood (fDNAml). Branches with poorly supported lengths have been collapsed. Bootstrap values (100 replicates) shown at the nodes were obtained by parsimony (above) and distance matrix (below) methods and added to the maximum likelihood tree. Only bootstrap values above $70 \%$ are shown. The scale bar represents 0.02 expected changes per site. Methanospirillum hungatei (accession no. M60880) was used as the outgroup.

1312C, 1313G, 1324C, and 1325G; Halorubrum (six recognized species and Natronobacterium vacuolatum; bases which are confined to the six recognized species are underlined), 114T, $179 \mathrm{~A}, 189 \mathrm{C}, 206 \mathrm{~A}, 611 \mathrm{G}, 683 \mathrm{C}, 783 \mathrm{C}, 794 \mathrm{G}, 795 \mathrm{G}, 818 \mathrm{C}$ $1070 \mathrm{C}, 1087 \mathrm{G}, 1101 \mathrm{G}, 1105 \mathrm{G}, 1115 \mathrm{C}, 1121 \mathrm{G}, 1127 \mathrm{C}, 1208 \mathrm{~A}$, and $1274 \mathrm{C}$; and Natronobacterium pharaonis, 55G, 64-, 65-, 71-, 72-, 73-, 85T, 109G, 381A, and 477C. The sequence numbers refer to the refined alignment ( 1 to 1483 ) as reported previously (8).

Sequences of spacer regions. Lengths (in base pairs) of the total spacer regions ranged from 528 (Halobacterium halobium) to 377 (Natronobacterium pharaonis). The values are as follows, together with the lengths before and after tRNA ${ }^{\mathrm{Ala}}$ genes: Halobacterium cutirubrum, 509, 105, and 332; Halobacterium halobium, 528, 105, and 351; Halococcus morrhuae, 433, 148, and 213; Haloferax volcanii, 391, 97, and 222; Natronobac- terium magadii, 405, 130, and 204; Natronobacterium gregoryi, 456, 154, and 230; Natronobacterium pharaonis, 377, 95, and 210; Natronobacterium vacuolatum, 480, 167, and 241; Halorubrum saccharovorum, 514, 161, and 281; Halorubrum sodomense, 517, 164, and 281; Halorubrum lacusprofundi, 509, 158, and 279; Halorubrum coriense, 512, 163, and 277; and Halorubrum distributum, 517, 164, and 281. Another species of the genus Halorubrum, Halorubrum trapanicum NRC 34021, was not available from the National Research Council since this strain died out at the National Research Council (11a).

Alignment of the 13 sequences was difficult and required the insertion of many gaps. However, it was clear that Natronobacterium vacuolatum showed the greatest similarity to members of the genus Halorubrum. The five recognized species of Halorubrum were easily aligned with Natronobacterium vacuolatum, and the alignment showed long stretches of conserved 
sequence. If sequences from members of the other genera were introduced, the alignment was severely disrupted. This was also reflected by the tRNA ${ }^{\text {Ala }}$ genes $(72 \mathrm{bp})$, which were largely conserved among the five Halorubrum spp. and $\mathrm{Na}$ tronobacterium vacuolatum, except for a one-base difference in Halorubrum lacusprofundi $\left({ }^{32} \mathrm{C} \rightarrow \mathrm{T}\right)$. Alignment with the other seven tRNA ${ }^{\text {Ala }}$ genes revealed differences in nine bases. Three of these (bases 5, 17, and 68) are conserved among the five recognized species of the Halorubrum-Natronobacterium vacuolatum group but differ from the other sequences, at bases 5 and 68 , which form a hydrogen bond, $\mathrm{T}$ and $\mathrm{A}$ in the Halorubrum-Natronobacterium vacuolatum group but $\mathrm{C}$ and $\mathrm{G}$ in the rest; and at base 17, which is in the D arm of the cloverleaf secondary structure, $\mathrm{C}$ in the Halorubrum- $\mathrm{Na}$ tronobacterium vacuolatum group but $\mathrm{T}$ in the rest.

\section{DISCUSSION}

In this study, phylogenetic tree reconstructions have clearly shown the genus Natronobacterium as being polyphyletic, i.e., it contains a diverse group of organisms that show closer relationships to widely differing groups within the family Halobacteriaceae. Each of the four current species probably belongs to a separate genus. Unlike the other halobacterial genera, which possess a variety of membrane glycolipids, the haloalkaliphiles contain only trace amounts or no glycolipids. Though phosphatidylglycerol and phosphatidylglycerophosphate-methyl ester are the main membrane phospholipids of the alkaliphiles as in the other genera, minor amounts of additional phospholipids (PL1 to PL4; only the structure of PL2 has been determined previously [11]) have been detected by thin-layer chromatography among the haloalkaliphiles $(14,15)$. $\mathrm{Na}$ tronobacterium gregoryi possesses phospholipids PL1 and PL3, Natronobacterium pharaonis has PL1, Natronobacterium magadii has PL3, and Natronobacterium vacuolatum contains PL3 and PL4. On the other hand, Natronococcus occultus has PL1 and PL2, while Natronococcus amylolyticus does not contain PL2 (9).

Since the phylogenetic data presented in this study indicate that each of the four species of the genus Natronobacterium probably belongs to a separate genus, the known differences in minor phospholipids may be considered as additional taxonomic markers.

We believe that the four species of the genus Natronobacterium belong to different genera as discussed below.

Natronobacterium gregoryi, which clustered tightly with the two species of the genus Natronococcus, should remain the type species of the genus Natronobacterium. This is supported by the four signature bases described above.

Natronobacterium pharaonis was only distantly related to the other taxa and would appear to represent a novel genus. Sequence comparisons with other $16 \mathrm{~S}$ rRNA genes, including that of the recently proposed species Haloarcula mukohataei (4), showed similarities of less than $89.9 \%$. Ten signature bases were also observed. We propose to transfer Natronobacterium pharaonis to Natronomonas gen. nov.

Natronobacterium vacuolatum showed a 16S rRNA sequence similarity of $95.6 \%$ to Halorubrum saccharovorum, the type species, indicating that they may belong to the same genus. In addition, a close examination of the 37 aligned sequences, used in reconstructing the tree, has revealed many sequence signatures. As described in Results, sequences of the six species of Halorubrum possess 19 genus-specific signature bases (i.e., not found in the other 31 sequences). The Natronobacterium vacuolatum sequence shares 16 of these 19 bases (the three bases which are confined to the six recognized species of Halorubrum are underlined). On the other hand, there are two positions (781 and 1406) where five of the six species and Natronobacterium vacuolatum have the same specific signature bases and two positions (1264 and 1265) where Halorubrum coriense (only) has different bases from the other 35 sequences. Furthermore, six bases, 785A, 793T, 1234G, 1242A, 1267T, and $1284 \mathrm{~A}$, were confined to the six recognized species of the genus Halorubrum, Natronobacterium vacuolatum, and Halobaculum gomorrense. Altogether, these data seem to support the view that Natronobacterium vacuolatum is related to members of the genus Halorubrum. No glycolipids have been detected in $\mathrm{Na}$ tronobacterium vacuolatum (15), whereas most of the species of the genus Halorubrum are characterized by the presence of glycolipid sulfated diglycosyldiether-3 (S-DGD-3) (7), but an exception has been reported, i.e., sulfated diglycosyldiether-5 (DGD-5) for Halonubrum trapanicum NRC 34021 (13). We cannot exclude the possibility that a trace amount of glycolipid is present in Natronobacterium vacuolatum.

Given the evidence from 16S rRNA gene sequences and the additional data from spacer region sequences, we believe there is a strong case to support the transfer of Natronobacterium vacuolatum to the genus Halorubrum and for the strain to be called Halorubrum vacuolatum (comb. nov.).

The 16S rRNA gene of Natronobacterium magadii showed a high sequence similarity to that of strain SSL1 (95.9\%) and to those of Natrialba asiatica $172 \mathrm{P} 1^{\mathrm{T}}$ (type strain) and Natrialba asiatica B1T (93.3 and 93.7\%, respectively). The similarity between SSL1 and Natrialba asiatica 172P1 and that between SSL1 and Natrialba asiatica B1T were 95.9 and $96.6 \%$, respectively. These figures (pairwise comparisons) seem to suggest that Natronobacterium magadii, strain SSL1, and Natrialba asiatica may be members of the same genus, Natrialba. On the other hand, the lipid analyses do not support the close 16S rRNA sequence similarities. No glycolipid has been detected in Natronobacterium magadii, but strain SSL1 has a minor amount of glycolipid DGD-4 (glucose $1 \rightarrow 6$ glucose-glycerol diether $[10,23])$. Natrialba asiatica has a glycolipid, S2-DGD (mannose-2,6-disulfate $1 \rightarrow 2$-glucose-glycerol diether [7]). The structures of these lipids suggest that the enzymes involved in the biosynthesis are different between the two. However, one of the two strains of Natrialba asiatica, B1T, is able to grow at alkaline $\mathrm{pH}$ (from 5 to 10) (7). Furthermore, Natronobacterium magadii and strain SSL1 do share one of the three signature bases of the genus Natrialba, 502G, and strain SSL1 shares 1108A. Moreover, 568A is confined to Natrialba asiatica B1T, Natronobacterium magadii, and strain SSL1. Altogether, these data (high similarities in $16 \mathrm{~S}$ rRNA genes, signature bases, and growth at alkaline $\mathrm{pH}$ ) seem to support the view that $\mathrm{Na}$ tronobacterium magadii and strain SSL1 are members of the genus Natrialba, and we propose to transfer Natronobacterium magadii to the genus Natrialba as Natrialba magadii and to call strain SSL1 Natrialba sp. strain SSL1.

The inferred tree (Fig. 1) also includes three species of the genus Halococcus (Halococcus saccharolyticus, Halococcus salifodinae, and Halococcus turkmenicus) and an unvalidated species of the genus Haloarcula, Haloarcula aidinensis (25). Validation of the latter species is currently in progress (26). Further taxonomic investigation of the three species of Halococcus will be described in a separate paper.

Description of Natronomonas gen. nov. Natronomonas Kamekura, Dyall-Smith, Upasani, Ventosa, and Kates (Na.tro .no.mo' nas. Gr. n. natron, derived from Arabic natrun, soda [sodium carbonate], Gr. fem. n. monas, unit; M.L. fem. n. Natronomonas, the soda unit). Gram-negative rods. Colonies are pigmented red because of the presence of $\mathrm{C}_{50}$-carotenoid.

Chemoorganotrophic and aerobic. Halophilic, requiring at 
least $2 \mathrm{M} \mathrm{NaCl}$. Alkaliphilic, growing between $\mathrm{pH} 7$ and 10 with optimum at 8.5 . Moles percent $\mathrm{G}+\mathrm{C}$ content of DNA is $64.3\left(T_{m}\right), 61.2$ to 62.1 (buoyant density). Polar lipids are glycerol-diether analogs of phosphatidylglycerol, methyl ester of phosphatidylglycerophosphate, phosphatidic acid, and an unknown phospholipid, PL1. Both diphytanyl moieties $\left(\mathrm{C}_{20}\right.$ and $\left.\mathrm{C}_{20}\right)$ and phytanyl-sesterterpanyl moieties $\left(\mathrm{C}_{20}\right.$ and $\left.\mathrm{C}_{25}\right)$ detected.

Type species is Natronomonas pharaonis.

Description of Natronomonas pharaonis (Soliman and Trüper 1982) comb. nov. (basonym, Natronobacterium pharaonis). The first alkaliphilic extreme halophile described. Pleomorphic motile rods, originally isolated from the alkaline brines of eutrophic desert lakes of Wadi Natrun, Egypt. Detailed characteristics are described elsewhere by Soliman and Trüper (18).

Type strain is Gabara, deposited with the Deutsche Sammlung von Mikroorganismen as DSM $2160^{\mathrm{T}}=$ ATCC $35678^{\mathrm{T}}=$ NCIMB $2260^{\mathrm{T}}$.

Strain SP1, which showed 96\% homology with DSM $2160^{\mathrm{T}}$ in DNA-DNA hybridization, was isolated from a Kenyan soda lake, Lake Magadi, and deposited as NCIMB 2191 (21). NCIMB 2191 contains a small amount of disesterterpanyl moiety $\left(C_{25}\right.$ and $\left.C_{25}\right)$, whereas DSM $2160^{\mathrm{T}}$ does not (19).

Description of Halorubrum vacuolatum (Mwatha and Grant 1993) comb. nov. (basonym, Natronobacterium vacuolatum). The properties of the type strain M24 (NCIMB 13189) were described previously (15).

Description of Natrialba magadii (Tindall et al. 1984) comb. nov. (basonym, Natronobacterium magadii). The properties of the type strain MS3 were described previously (21).

\section{REFERENCES}

1. Devereux, R., S.-H. He, C. L. Doyle, S. Orkland, D. A. Stahl, J. LeGall, and W. B. Whitman. 1990. Diversity and origin of Desulfovibrio species: phylogenetic definition of a family. J. Bacteriol. 172:3609-3619.

2. Fry, N. K., S. Warwick, N. A. Saunders, and T. M. Embley. 1991. The use of $16 \mathrm{~S}$ ribosomal RNA analyses to investigate the phylogeny of the family Legionellaceae. J. Gen. Microbiol. 137:1215-1222.

3. Grant, W. D., and H. Larsen. 1989. Group III. Extremely halophilic archaeobacteria, p. 2216-2233. In J. T. Staley, M. P. Bryant, N. Pfennig, and J. G. Holt (ed.), Bergey's manual of systematic bacteriology, vol. 3. Williams \& Wilkins, Baltimore, Md.

4. Ihara, K., S. Watanabe, and T. Tamura. 1997. Haloarcula argentinensis sp. nov. and Haloarcula mukohataei sp. nov., two new extremely halophilic archaea collected in Argentina. Int. J. Syst. Bacteriol. 47:73-77.

5. International Journal of Systematic Bacteriology. 1996. Validation of the publication of new names and new combinations previously effectively published outside the IJSB. List no. 56. Int. J. Syst. Bacteriol. 46:362-363.

6. International Journal of Systematic Bacteriology. 1996. Validation of the publication of new names and new combinations previously effectively published outside the IJSB. List no. 57. Int. J. Syst. Bacteriol. 46:625-626.

7. Kamekura, M., and M. L. Dyall-Smith. 1995. Taxonomy of the family
Halobacteriaceae and the description of two new genera Halorubrobacterium and Natrialba. J. Gen. Appl. Microbiol. 41:333-350.

8. Kamekura, M., and Y. Seno. 1993. Partial sequence of the gene for a serine protease from a halophilic archaeum Haloferax mediterranei $\mathrm{R} 4$, and nucleotide sequences of 16S rRNA encoding genes from several halophilic archaea. Experientia 49:503-513.

9. Kanai, H., T. Kobayashi, R. Aono, and T. Kudo. 1995. Natronococcus amylolyticus sp. nov., a haloalkaliphilic archaeon. Int. J. Syst. Bacteriol. 45:762-766.

10. Kates, M. 1993. Membrane lipids of extreme halophiles: biosynthesis, function and evolutionary significance. Experientia 49:1027-1036.

11. Lanzotti, V., B. Nicolaus, A. Trincone, M. DeRosa, W. D. Grant, and A Gambacorta. 1989. A complex lipid with a cyclic phosphate from the archaebacterium Natronococcus occultus. Biochim. Biophys. Acta 1001:31-34.

11a.Latta, R. Personal communications.

12. Lodwick, D., H. N. M. Ross, J. A. Walker, J. W. Almond, and W. D. Grant. 1991. Nucleotide sequence of the 16S ribosomal RNA gene from the haloalkaliphilic archaeon (archaebacterium) Natronobacterium magadii, and the phylogeny of halobacteria. Syst. Appl. Microbiol. 14:352-357.

13. McGenity, T. J., and W. D. Grant. 1995. Transfer of Halobacterium saccharovorum, Halobacterium sodomense, Halobacterium trapanicum NRC34021 and Halobacterium lacusprofundi to the genus Halorubrum gen. nov., as Halorubrum saccharovorum comb. nov., Halorubrum sodomense comb. nov., Halorubrum trapanicum comb. nov., and Halorubrum lacusprofundi comb. nov. Syst. Appl. Microbiol. 18:237-243.

14. Morth, S., and B. J. Tindall. 1985. Variation of polar lipid composition within haloalkaliphilic archaebacteria. Syst. Appl. Microbiol. 6:247-250.

15. Mwatha, W. E., and W. D. Grant. 1993. Natronobacterium vacuolatum sp. nov., a haloalkaliphilic archacon isolated from Lake Magadi, Kenya. Int. J. Syst. Bacteriol. 43:401-404.

16. Oren, A., and A. Ventosa. 1996. A proposal for the transfer of Halorubrobacterium distributum and Halorubrobacterium coriense to the genus Halonubrum as Halorubrum distributum comb. nov. and Halorubrum coriense comb. nov., respectively. Int. J. Syst. Bacteriol. 46:1180.

17. Oren, A., P. Gurevich, R. T. Gemmell, and A. Teske. 1995. Halobaculum gomorrense gen. nov., sp. nov., a novel extremely halophilic archaeon from the Dead Sea. Int. J. Syst. Bacteriol. 45:747-754.

18. Soliman, G. S. H., and H. G. Trüper. 1982. Halobacterium pharaonis sp. nov., a new, extremely haloalkaliphilic archaebacterium with low magnesium requirement. Zentralbl. Bakteriol. Hyg. Abt. I Orig. C3:318-329.

19. Tindall, B. J. 1985. Qualitative and quantitative distribution of diether lipids in halophilic archaebacteria. Syst. Appl. Microbiol. 6:243-246.

20. Tindall, B. J. 1992. The family Halobacteriaceae, p. 754-808. In A. Balows, H. G. Trüper, M. Dworkin, W. Harder, and K.-H. Schleifer (ed.), The prokaryotes, 2nd ed., vol. I. Springer-Verlag, New York, N.Y.

21. Tindall, B. J., H. N. M. Ross, and W. D. Grant. 1984. Natronobacterium gen. nov. and Natronococcus gen. nov., two new genera of haloalkaliphilic archaebacteria. Syst. Appl. Microbiol. 5:41-57.

22. Upasani, V., and S. Desai. 1990. Sambhar salt lake. Chemical composition of the brines and studies on haloalkaliphilic archaebacteria. Arch. Microbiol. 154:589-593.

23. Upasani, V. N., S. G. Desai, N. Moldoveanu, and M. Kates. 1994. Lipids of extremely halophilic archaeobacteria from saline environments in India: a novel glycolipid in Natronobacterium strains. Microbiology 140:1959-1966.

24. Winker, S., and C. R. Woese. 1991. A definition of the domains Archaea, Bacteria, and Eucarya in terms of small subunit ribosomal RNA characteristics. Syst. Appl. Microbiol. 14:305-310.

25. Xu, Y., H. Liu, and P. Zhou. 1995. Nucleotide sequence of the 16S rRNA from an archaea, Haloarcula aidinensis strain B2. Acta Microbiol. Sin. 35: 77-85.

26. Zhou, P. Personal communication. 